\title{
LIVRO DIDÁTICO E A PEDAGOGIA DO MESTRE IGNORANTE
}

\section{TEXTBOOKS AND THE PEDAGOGY OF THE IGNORANT SCHOOLMASTER}

\section{Carlos Renato Lopes*}

\begin{abstract}
RESUMO
$\mathrm{O}$ artigo discute as ideias apresentadas pelo filósofo francês Jacques Rancière em $\mathrm{O}$ Mestre Ignorante (1987/2002) quanto a suas possíveis relações com a produção e circulação de livros didáticos para o ensino básico. Particularmente, observa-se como o livro didático pode reforçar o que o autor chama de lógica da explicação, intensificando a hierarquia das inteligências e a condição de desigualdade em nome de uma igualdade ainda por vir, mas também como ele pode interromper essa lógica, funcionando como uma fonte mediadora de duas vontades a serviço de uma única inteligência: a que possibilita que tanto o professor como o aluno aprendam e ensinem aquilo que ainda não sabem. Como suporte para a discussão, referimo-nos a alguns trechos de editais do governo federal relativos à elaboração de coleções de livros didáticos de língua estrangeira moderna.
\end{abstract}

Palavras-chave: livro didático; lógica da explicação; Jacques Rancière.

\section{ABSTRACT}

The article discusses the ideas presented by the French philosopher Jacques Rancière in The Ignorant Schoolmaster (1987/2002) as to their possible relations with the production and circulation of textbooks for primary and secondary education. Particularly, we observe how textbooks can reinforce what the author calls the logic of explanation, intensifying the hierarchy of intelligences and the condition of inequality for the sake of an equality yet to come, but also how they can interrupt this logic, functioning as a mediating instance between two wills working under only one intelligence: that which enables both teacher and student to learn and teach what they still do not know. In order to support our discussion, we take as reference a few excerpts from national official documents concerning the design of foreign language textbooks.

Keywords: textbook; logic of explanation; Jacques Rancière.

A sociedade só existe pelas distinções, e a natureza não apresenta senão igualdades. É impossível que a igualdade subsista de fato por muito tempo; mas, mesmo quando destruída, ela permanece ainda a única explicação razoável para as distinções convencionais.

- Joseph Jacotot, $1830 .^{1}$

\footnotetext{
* UNIFESP, Guarulhos (SP), Brasil. carelo@uol.com.br
} 
A explicação não é necessária para socorrer uma incapacidade de compreender. É, ao contrário, essa incapacidade.

- Jacques Rancière, 1987/2002, p. 20.

\section{INTRODUÇÃO}

Pesquisas em Linguística Aplicada têm lançado múltiplos olhares sobre o papel e o funcionamento dos materiais didáticos no ensino de línguas materna e estrangeira. Somente no Brasil, trabalhos recentes incluem contribuições que vão desde a análise do discurso (em suas diversas vertentes) aos estudos críticos, passando pelas teorias de multiletramentos/novos letramentos e de gêneros textuais/ discursivos ${ }^{2}$. No presente artigo oferecemos um aporte ainda pouco explorado nessa frente de investigação: as reflexões pedagógicas propostas pelo filósofo francês contemporâneo Jacques Rancière ${ }^{3}$. Mais conhecido por suas teorias sobre política e estética, Rancière não se debruçou especificamente sobre questões de educação exceto na obra O Mestre Ignorante (1987/2002), cuja influência, no entanto, seguiu se observando em diversos estudos na área mais específica da pedagogia ${ }^{4}$.

No que concerne ao campo de estudos da linguagem mais diretamente, tal influência ainda pouco se distingue, embora vejamos a oportunidade de um diálogo relevante e desejável, não no sentido de se "aplicar", propriamente, o pensamento de Rancière às pesquisas aí empreendidas, mas antes no sentido de traçar uma aproximação crítica e interdisciplinar entre esse pensamento e as teorias de ensinoaprendizagem no contexto da formação de professores de língua.

Nesse sentido, apresentamos primeiramente uma breve descrição das linhas gerais do pensamento de Rancière exposto em O Mestre Ignorante (1987/2002), para na sequência dar partida à discussão das questões pontuais que nos guiam aqui, a saber: como as condições de produção e circulação de materiais didáticos (particularmente as coleções didáticas) no ensino básico brasileiro podem ser problematizadas com base nas reflexões de Rancière acerca do que chama de lógica da explicação, e quais são os possíveis efeitos que tal problematização pode trazer no trabalho cotidiano em sala de aula. Como apoio para nossa discussão, tomamos

1 Citado em Rancière, 1987/2002, p. 96.

2 Dentre esses trabalhos, destacamos Braga (2014); Ferreira (2014); Dias \& Cristóvão (2009); Tilio (2006); e Rojo \& Batista (2003).

3 Há, porém, de se mencionar Coracini (2014) e Jordão (2014), dois trabalhos mais recentes que promovem uma aproximação entre a Linguística Aplicada e a obra de Rancière de perspectivas, porém, um pouco distintas da aqui apresentada.

4 Dentre esses últimos, destacamos Trevisan (2010); Skliar (2003); e Valle (2003). 
trechos de editais do PNLD (Programa Nacional do Livro Didático) propostos pelo governo federal brasileiro para a elaboração de coleções didáticas - no caso aqui, especificamente os de língua estrangeira moderna - nos quais algumas das questões levantadas por Rancière encontram, por um lado, ressonância e, por outro, pontos de atrito. Concluímos o artigo com uma proposta mínima rumo a uma atitude mais crítica e transformadora - dentro do que chamaremos de lógica da reapropriação - em relação ao uso de livros didáticos como mediadores das práticas de ensinoaprendizagem empreendidas no cotidiano das aulas de língua do ensino básico.

\section{JACOTOT-RANCIÈRE E A PEDAGOGIA DO MESTRE IGNORANTE}

Em O Mestre Ignorante (1987/2000), Rancière relata a trajetória de um professor francês do início do século XIX chamado Joseph Jacotot. Em certa ocasião, ele propôs a seus alunos holandeses, falantes de flamenco que não sabiam uma palavra de francês, que lessem com a ajuda do texto em versão bilíngue o romance Télémaque, de François Fénelon (1699). Ao cabo de um tempo, o que parecia a princípio uma façanha, tornara-se possível: os alunos haviam aprendido a ler em francês sem que o mestre tivesse que lhes explicar nada, somente de aproximação em aproximação ou seja, haviam aprendido sem passar pela lógica tradicional da explicação.

Por lógica da explicação Rancière entende a operação, corriqueira nas práticas educacionais nos mais variados contextos, que se desdobra por meio prioritariamente de instruções orais, tanto para o que se deve fazer quanto para o que se deve aprender. $\mathrm{O}$ professor precisa explicar oralmente aquilo que está escrito e que o aluno tem de entender. Tal operação confere ao professor o poder de instaurar a compreensão, como um ato ex nibilo. É falando que o professor "inaugura" o saber. E é ele quem decide o quanto é preciso explicar, ou até onde ele deve ir para que se instaure o conhecimento. Quando considera a operação suficiente, interrompe-a, de modo que a inteligência do aluno passa, supostamente, a encenar a submissão à inteligência do professor. Trata-se, portanto, de uma operação em que uma inteligência se sobrepõe a outra inteligência.

Rancière nos mostra que a lógica da explicação contrapõe-se ao mecanismo da tradução, entendida aqui como reapropriação de sentidos. Toda leitura, todo trabalho didático deveria envolver, antes de qualquer coisa, uma operação de tradução, de uma inteligência autônoma a outra inteligência autônoma. Sabe-se sempre aquilo que já se sabe. Para aprender coisas novas, é preciso que a inteligência, dotada da autonomia que lhe permite desde bem cedo adquirir uma língua (ou andar de 
bicicleta, ou tocar um instrumento), seja posta em ação para reacomodar o novo desafio ao repertório por ela já "sabido".

Para Rancière, portanto, reverter a lógica da explicação por uma lógica da tradução envolveria uma operação que impõe, acima de tudo, uma vontade sobre outra vontade. Nessa operação, o aluno seria instado a aprender o que quisesse desde que sua vontade assim se dispusesse. Tratar-se-ia de emancipar intelectualmente o aluno para que, tendo despertado em si o interesse de aprender algo, pudesse fazê-lo por si só, numa condição que o iguala a qualquer outro ser humano que aprende.

Inspirado por Jacotot, Rancière trabalha de modo peculiar com o conceito de igualdade: algo que não corresponde a um ideal político ou ético (uma condição a ser atingida), mas que funciona como um princípio ou axioma epistemológico a partir do qual se pode pensar e agir. Ao invés de pressupor a desigualdade e tomar a igualdade como um ideal desejável, ainda que distante, o autor propõe que partamos da presunção de igualdade, pois esta é a condição que torna a desigualdade possível (RUITENBERG, 2008). Tal presunção descarta qualquer possível vínculo entre intelecto e posição de ordem social, uma vez que não há nenhuma explicação racional ou princípio legítimo que justifique a distribuição de papeis na organização social. Nesse sentido, o filósofo francês concebe a igualdade como a inexistência de razão ou explicação para a desigualdade (PELLETIER, 2012).

Como é possível falar de igualdade no contexto da pedagogia? Rancière lembra que antes de passarem pelo sistema formal da escola, todos os sujeitos são falantes de uma língua materna. Eles a adquirem sendo expostos a ela, convivendo com ela, sem que nada lhes seja preciso explicar. Trata-se da aquisição autônoma por excelência, a que todos, independentemente de classe social, raça ou gênero, são capazes de exercitar. Seria o caso, portanto, de admitir o que tacitamente já se sabe desde sempre: que adquirimos uma série de conhecimentos no dia-a-dia para as quais não recebemos qualquer explicação formal. Fazemos isso porque somos capazes de vivenciar, manipular, explorar as coisas - inclusive uma língua estrangeira.

Para que o chamado método universal de Jacotot - na verdade, um nãométodo - fosse contemplado em toda sua especificidade, seria preciso que também o professor não soubesse aquilo que está sendo ensinado. Tal condição facilitaria, ou mesmo evidenciaria, a distinção entre a ordem das coisas sabidas e os efeitos de poder que a divisão saber-não saber pode causar. De um lado, seria possível pensar, no contexto de ensino de uma língua estrangeira, por exemplo, que muitos professores, dado o insuficiente preparo com que iniciam a profissão, efetivamente pouco saibam sobre a língua e que dessa maneira estejam também eles próprios aprendendo junto. 
Porém, seria possível igualmente pensar que o professor, sabendo pouco (ou muito) mais que os alunos, tivesse que provocar aquele afastamento, agir conscientemente sobre aquela distinção de modo a que sua condição de conhecedor fosse mitigada e abrisse espaço para uma emancipação real por parte de seus alunos. Neste segundo caso, seria preciso que toda suspeitável opacidade da língua estrangeira - suas barreiras, suas interdições, os efeitos de estranhamento gerados por suas diferenças irreconciliáveis: enfim, sua materialidade irredutível fosse trabalhada como uma nova descoberta, um novo confronto rumo a um estado diferente de conhecimento, ou seja, como um deslocamento de fato experimentado pelos aprendizes.

Tratar-se-ia de o professor assumir papel semelhante ao de um total beginner - muito provavelmente a condição em que ele próprio se encontraria caso se aventurasse a aprender uma terceira, quarta língua (chinês ou russo para um brasileiro, digamos). Tratar-se-ia de colocar em teste a presunção de uma igualdade de inteligências - a capacidade igualmente facultada (embora desigualmente instanciada) de entender enunciados linguísticos, de narrar, de simbolizar as experiências para além de qualquer ontologia ou teleologia.

O mestre ignorante é, fundamentalmente, aquele que decide "ignorar" no sentido de "desprezar" ou mesmo "sublimar" - a desigualdade que sustenta as práticas pedagógicas. Nos termos de Rancière:

O mestre ignorante é o mestre que não quer saber das razões da desigualdade. Toda experiência pedagógica normal está estruturada por razões da desigualdade. O mestre ignorante é aquele que ignora tudo isso e que comunica essa ignorância, isso é, comunica essa vontade de não saber nada a esse respeito [...] É preciso que [ele] decida que as inteligências são iguais. No entanto, essa decisão não é uma operação meramente intelectual, mas também da vontade, no sentido de uma operação que reestrutura as relações entre os homens. Eis toda a lógica da coisa. (em entrevista a VERMEREN et al, 2003, p. 192-3)

A igualdade de inteligências - no caso a do mestre e a dos alunos - é, portanto, para Rancière, um princípio epistemológico que precisa ser constantemente verificado. É uma bipótese que investe contra o que se tende a fazer intuitivamente nas práticas hierarquizadas da pedagogia - um investimento para além da mera constatação, por exemplo, de que compartilhamos uma mesma língua quando nos comunicarmos com os outros e que por isso somos capazes de operar em um nível mínimo de igualdade. A consciência da contingência das relações de saber-poder que permeiam a instituição pedagógica torna-se condição para uma encenação concreta dessa igualdade, em um contexto específico, entre sujeitos específicos, em uma instância particular do que Rancière (2000/2009) chama de partilha do sensivel, que é 
a condição pré-estabelecida e normatizada de distribuição, na organização social, daquilo que se pode ver, dizer e tomar como próprio (in-corporar) da experiência.

A verificação da igualdade trabalha para negar a presunção de que determinados modos de ser e sentir se relacionem diretamente a determinadas aptidões, promovendo o entendimento de que é possível aos indivíduos estarem onde supostamente não poderiam/deveriam estar, ou fazer algo que supostamente não poderiam/saberiam fazer. Tal entendimento problematiza a visão pela qual o aluno é capaz de reivindicar superioridade intelectual sobre os outros - pares ou crianças mais novas - justamente porque reconhece a superioridade intelectual do professor da escola, assim como este é capaz de reivindicar superioridade intelectual sobre os alunos porque reconhece a superioridade intelectual do professor universitário sobre ele. O desafio reside não em legitimar essa visão, mas sim suspender todo o sistema de reconhecimento bem como a satisfação perversa que ele proporciona (PELLETIER, 2012; VALLE, 2003), ambos sustentados pela presunção de desigualdade que preside o funcionamento das instituições educacionais.

Mas como intercederia, no cenário dessa possível abertura para a emancipação intelectual, um poderoso instrumento das práticas pedagógicas: o livro didático? Seria o livro didático um agente material facilitador de tal abertura por parte do professor? Ou seria ele, antes, um elemento ainda mais legitimador do poder-saber historicamente atribuído ao professor e, portanto, pouco contribuiria para uma real divisão entre conhecimento e poder? Ao traçar detalhadamente o mapa do que deve ser ensinado, e o modo como isso deveria ser feito, não estaria o livro didático reduplicando o poder da lógica explicativa, tão antitético, para Jacotot-Rancière, ao poder emancipatório de uma pedagogia do mestre ignorante?

\section{A LÓGICA DA EXPLICAÇÃO E O LIVRO DIDÁTICO}

As reflexões e questionamentos acima delineados serão tomados como apoio para discutirmos, neste artigo, algumas questões relativas às condições de produção do livro didático para o ensino básico no Brasil, enfocando em particular os recentes editais do PNLD (Programa Nacional do Livro Didático) para a elaboração de coleções didáticas para o ensino fundamental e médio. Uma primeira aproximação se relaciona ao fato de que nesses editais é patente a preocupação com que as coleções contenham insumos teórico-metodológicos com anotações para o professor sobre o tipo de trabalho a ser realizado em sala de aula. A tônica é de que os manuais precisam sempre contextualizar... explic(it)ar aos professores a teoria 
que sustenta as práticas, ainda que a proposta geral seja a de firmar o "compromisso com a valorização dos saberes advindos da experiência do professor, favorecendo a aproximação respeitosa entre saberes teóricos e saberes práticos" (BRASIL, 2012, p. 67).

Ora, se a lógica da explicação passava por o professor reproduzir em discurso oral a ordem da palavra escrita, a qual contivesse em si já todo o teor do que se deve aprender, no Manual do Professor há um desdobramento suplementar, quase labiríntico dessa lógica: o livro didático explica ao professor o que este deve explicar a respeito do que poderia, a princípio, ser autoexplicável.

Assim como, para Rancière, o mestre precisa dos alunos para que se confirme a instauração de um saber, com o livro didático temos um "aprofundamento" dessa lógica, pela qual uma instância de poder-saber legitima a outra de modo circular: o livro ensina aquilo que o professor deve ensinar. Como manual didático, ele não somente delimita o que deve pertencer à ordem do explicável, mas também, de certa forma, silencia aquilo que os editais ou os parâmetros neutralizam, isto é, os elementos de um contexto que, por meio destes documentos, decidiu-se excluir da ordem do discurso do livro didático.

Rancière não trata propriamente da questão do manual didático tal como fazemos aqui. Mas algumas conexões podem ser traçadas. De forma genérica, ele trata o livro, qualquer livro usado na escola, como um exemplo de instrumento operante na lógica da explicação. O uso do livro, tal qual tradicionalmente se dá nas práticas pedagógicas, sugere a Rancière alguns questionamentos:

\footnotetext{
Eis, por exemplo, um livro entre as mãos do aluno. Esse livro é composto de um conjunto de raciocínios destinados a fazer o aluno compreender uma matéria. Mas, eis que, agora, o mestre toma a palavra para explicar o livro. Ele faz um conjunto de raciocínios para explicar o conjunto de raciocínios em que o livro se constitui. Mas, por que teria o livro necessidade de tal assistência? Ao invés de pagar um explicador, o pai de família não poderia, simplesmente, dar o livro a seu filho, não poderia este compreender, diretamente, os raciocínios do livro? $\mathrm{E}$, caso não o fizesse, por que, então, compreenderia melhor os raciocínios que lhe explicarão aquilo que não compreendeu? Teriam esses últimos uma natureza diferente? E não seria necessário, nesse caso, explicar, ainda, a forma de compreendê-los? (RANCIĖRE, 1987/2002, p. 16)
}

Entretanto, da mesma forma que o livro pode funcionar a serviço da lógica hierarquizante das inteligências - ou seja, da desigualdade -, ele continua sendo um instrumento que pode estabelecer um grau inicial de mediação entre professor e aluno. Trata-se de um dispositivo material, sempre disponível, para a verificação de que os alunos prestaram atenção e direcionaram sua inteligência, a qual, nessas condições, se mantém a igual distância da inteligência do professor (GALLOWAY, 
2012, p. 177-8). Nesse sentido, o livro teria a função não de explicar, nem tampouco precisaria ser explicado. Ele poderia ser usado para suscitar, estabelecer condições básicas de interpretação e construção de sentidos. Ao expor o aluno ao texto (imagem, poema, obra de arte), caberia ao professor lançar basicamente três perguntas que funcionariam como "gatilhos": 1. O que você está vendo?; 2. O que você acha disso (i.e. qual sua opinião sobre isso?); e 3. Que sentido você dá a isso? (RANCIÈRE, 1987/2002, p. 34-5).

Enquanto que, em um nível mais imediato, as perguntas trabalhariam a questão da interpretação e construção de sentidos, seus efeitos e implicações poderiam ter um alcance maior, agindo sobre o próprio modo de constituição das subjetividades envolvidas nas práticas pedagógicas. Conforme aponta Biesta (2006) com base no pensamento de Hannah Arendt, o exercício de continuamente (se) fazer esse tipo de pergunta poderia apontar para um modo de os sujeitos se tornarem únicos, por meio de práticas concretas de encontro com o outro, com a diferença. Segundo Arendt, os sujeitos só passam a ser sujeitos quando agem, ou seja, quando conseguem "trazer os seus começos" (bring their beginnings) para um contexto em que outros também podem agir e propor seus próprios "começos", e a partir daí seguir respondendo sem que se possa, no processo, ter qualquer garantia sobre os desdobramentos possíveis de cada uma das respostas. O objetivo da educação, por esse raciocínio, seria o de oferecer o mais frequentemente possível oportunidades para que sujeitos "se façam presentes" (come into presence) ao trazer para o encontro seus "começos" e agir sobre os "começos" dos outros de modo, fazendo-se únicos. Conforme argumenta Biesta:

[A responsabilidade educacional] implica fazer uma pergunta simples mas, na minha opinião, fundamental: "O que você acha disso?"[...] Esta é uma pergunta difícil, uma pergunta com o potencial de questionar. No entanto, gostaria de argumentar que é também uma questão com o potencial de convocar alguém a ser um indivíduo único, singular. É importante ver que essa pergunta pode ser feita de muitas formas diferentes. [...] Ela também pode ser feita de formas não-verbais; por exemplo, abordando o currículo não como um conjunto de conhecimentos e habilidades que tem de ser transferido para as mentes e os corpos de nossos alunos, mas como um conjunto de práticas e tradições que demandam dos alunos uma resposta e que fornecem maneiras diferentes aos recém-chegados de responder e vir ao mundo. (BIESTA, 2006, p. 150$)^{5}$

Se, para Rancière, a emancipação intelectual é um resultado possível (embora não necessário e muito menos garantido) da prática pedagógica, isso se dá porque o que ela faz não é revelar o mundo do conhecimento ao aluno, mas antes revelar uma inteligência a si mesma. De modo análogo, para Biesta educar é permitir aos sujeitos

5 Tradução nossa, como nas demais citações neste artigo de originais em inglês. 
que se façam presentes. E, nesse sentido, qualquer texto, qualquer livro didático poderia ser utilizado como recurso para tal fim.

O raciocínio, enquanto radical em sua proposta, encontra na institucionalidade da educação barreiras que o tornam impraticável como pedagogia. A ideia de uma função global e social da escola como instituição não se confunde com a capacidade de servir como fonte de conhecimento, seja este qual for. Há que se separar "a capacidade de ser, para um outro, a fonte de uma igualdade exercitada [an enacted equality] da ideia de uma instituição social encarregada de atingir [achieving] a igualdade" (RANCIÈRE, 2010, p. 14).

No que se refere especificamente à produção e circulação do livro didático, a institucionalidade começa a funcionar já no fato de que há critérios que regulam a escolha do livro a ser adotado, a viabilidade comercial do livro no mercado editorial, e até mesmo a possibilidade de simplesmente não se usar livro algum em sala de aula (RAMOS, 2009; KUMARAVADIVELU, 2012). Mas há também uma outra dimensão da institucionalidade que tem a ver com os regimes discursivos que orientam o funcionamento do livro didático como agente estruturador de uma visão particular do que significa ensinar e aprender determinados conteúdos. Abordaremos essas questões a seguir, utilizando como objeto o livro didático de língua estrangeira.

\section{CONDIÇÕES DE PRODUÇÃO DO LIVRO DIDÁTICO: O PNLD}

Tomemos, para uma primeira ilustração, o edital do PNLD 2014, que se destina à proposta de coleções didáticas para as séries finais do ensino fundamental $\left(6^{\circ}\right.$ a $9^{\circ}$ anos). Ali consta, entre um grande número de critérios e recomendações gerais, a determinação de que não se mencione nenhuma marca comercial ou nome de produto nos textos do material. Trata-se de condição excludente das coleções - uma espécie de "cláusula de justa causa" para a eliminação de uma coleção do processo seletivo.

Imaginemos uma atividade, passível de inclusão em um livro didático, em que uma determinada marca de refrigerante (digamos, a Coca-Cola) apareça dentro de um contexto específico: uma campanha publicitária dos anos 1950 que, juntamente com outras campanhas publicitárias desta e de épocas posteriores, integrasse um painel de imagens ilustrativas de um certo estilo de vida - um conjunto de comportamentos, vestimentas, relações familiares - a serem discutidas pelos alunos na sequência de uma atividade de compreensão oral. 
Tal contextualização, a princípio isenta de qualquer interesse que não pedagógico, seria pela "lógica preventiva" do edital do livro didático motivo insuficiente para a abertura de uma "brecha" no regulamento. Dado que o edital antecipa o contexto, delimitando de antemão aquilo que pode ou não figurar no livro didático, ele tende a ignorar a possibilidade de reflexão contemplada por outros contextos, agindo, dessa forma, de modo paradoxal: é preciso contextualizar, mas o contexto já deve estar previsto. Dá-se aí uma operação que não apenas silencia o que pode ser trazido de outros contextos como impede sua reapropriação (ou tradução) por parte de alunos e professores.

Este é apenas um exemplo de restrições que afetam a produção do livro didático. Suponhamos que o livro didático que chega às mãos do professor é um desses que tenha sido aprovado no edital e que portanto segue, em sua maior parte, os parâmetros bastante detalhados de confecção dos materiais. Que garantia pode haver de que uma série de outras restrições não irá tomar lugar no trabalho cotidiano da sala de aula? O princípio da hierarquização de inteligência certamente não é abolido por força de se usar como referência um material que atenda a princípios defensáveis como os que balizam a confecção dos materiais. De fato, há nos editais orientações bastante condizentes, pelo menos em princípio, com o que se poderia chamar de educação emancipatória. Vejamos três trechos de Editais do PNLD de Língua Estrangeira Moderna relativos especificamente ao Manual do Professor:

- (T1) Na avaliação das coleções de Língua Estrangeira Moderna, será observado se o Manual do Professor [...] apresenta sugestões de implementação das atividades, porém evitando detalhamentos que possam impedir a criatividade e autonomia do professor. (BRASIL, 2009, p. 62)

- (T2) O manual do professor, especialmente, deve valorizar os conhecimentos prévios do aluno e buscar a confrontação com o conhecimento científico, esclarecendo a relação entre o conhecimento historicamente construído e aquele construído em seu cotidiano. (BRASIL, 2012, p. 55)

- (T3) As concepções atuais de ensino e aprendizagem, assim como as orientações para formação docente, consideram que é preciso superar a dicotomia entre os que produzem e os que ensinam os conhecimentos e repensar o papel do professor, valorizando sua competência também como produtor do saber. Portanto, o manual do professor não deve ser um mero roteiro para utilização do livro do aluno, com acréscimo de textos desarticulados da proposta central da coleção. (BRASIL, 2012, p. 56) 
É possível traçar algumas ligações entre esses trechos e identificar neles algumas convergências quando justapostos. Basicamente, trabalha-se aqui com a ideia de autonomia e flexibilização. O professor e o aluno devem ter seus conhecimentos práticos valorizados, e o Manual do Professor não pode "esgotar" as possibilidades de condução da prática pedagógica justamente por não ser possível antecipar quais conhecimentos serão mobilizados por ambas as partes nas instâncias concretas de trabalho com o material em sala de aula. Pressupõe-se também a possibilidade de que o compartilhamento de conhecimentos práticos se dê de forma horizontal, entre alunos, por meio de práticas que potencializam a valorização dos sujeitos como produtores de conhecimento. É o que ocorre, mais comumente, em um class project, por exemplo.

No entanto, é possível também apontar aí uma contradição. A insistência em se manter uma suposta coerência teórico-metodológica com a proposta central da coleção corre o risco de se sobrepor sobre a heterogeneidade de conhecimentos práticos os quais, frequentemente, subjazem às ações contingentes de professores e alunos ao longo do processo. Se, conforme sugere o edital, o professor possui a competência de produzir saber, e se esta deve ser valorizada, como é possível antecipar que essa produção seja condizente com a proposta teórico-metodológica da coleção? Como é possível manter-se dentro do discurso "verdadeiro" do livro didático sem que, de alguma forma, a variedade de saberes que o professor traz para as práticas - tradicionais ou inovadores, em maior ou menor grau - seja posta em questão?

Parece-nos que o Manual do Professor, por mais sensível que possa ser a essas questões, terá sempre o papel de indicar um caminho de coerência, de conformidade a uma concepção determinada de ensino-aprendizagem para a qual haverá sempre uma lógica da explicação que a retomará como horizonte final. $\mathrm{Ou}$ seja, a valorização dos saberes prévios, tanto de professores como alunos, tende a funcionar como uma etapa no caminho rumo a uma aprendizagem segura e condizente com um princípio norteador adaptável aos demais contextos, e não como um ponto de parada, um ponto de inflexão epistemológica em que formas de conhecer possam eventualmente, por sua natureza inconciliável, entrar em rotas de colisão. Como não nos deixa esquecer Valle (2003), a injunção metodológica de se "partir da realidade do aluno", quando tornada princípio fundamental de valoração epistemológica, ou profissão de fé - e ela o é cada vez mais na educação brasileira, desde a Escola Nova -, comporta ela própria um grau de mistificação: "uma falácia lógica evidente, somente sustenta pela posição de um mestre [ou, igualmente, de 
seu Manual] que conhece antecipadamente e melhor do que o próprio aluno qual é sua realidade" (p, 263-264).

Três outros trechos dos editais, relativos a parâmetros gerais para submissão de coleções didáticas, chamam particularmente a atenção pelo que propõem se excluir, ou incluir/valorizar:

- (T4) Serão excluídas as coleções que não atenderem aos seguintes requisitos: [...] favorecer o desenvolvimento de capacidades básicas do pensamento autônomo e crítico, no que diz respeito aos objetos de ensino-aprendizagem propostos. (BRASIL, 2012, p. 56)

- (T5) Serão excluídas do PNLD 2014 as coleções que [...] veicularem estereótipos e preconceitos de condição social, regional, étnico-racial, de gênero, de orientação sexual, de idade ou de linguagem, assim como qualquer outra forma de discriminação ou de violação de direitos. (BRASIL, 2012, p. 55)

- (T6) É fundamental, portanto, focalizar as línguas não somente como formas de expressão e comunicação, mas como espaços de construção de conhecimento, como portadoras de valores e sentimentos e como constituintes de significados e sentidos profundamente atrelados a processos históricos. (BRASIL, 2009, p. $55-6)$

Observa-se aqui, mais nitidamente, a forma como o discurso do edital pode gerar efeitos de sentido que apontam para o cerceamento das significações atribuíveis à diferença, colocando-se de antemão uma barra sobre quaisquer posicionamentos discursivos que remetam a preconceitos e estereótipos. Ora, como garantir que tais posicionamentos possam ser transformados se a mera presença deles é negada, sob o risco de o material ser rejeitado antes mesmo de poder chegar às mãos do professor? Se o material não pode conter materiais preconceituosos, é pouco provável que os alunos entrem em contato com eles por essa via, o que de certa forma lhes priva de um exercício interpretativo de real confronto entre discursos os quais, afinal, podem bem fazer parte do repertório de conhecimentos tácitos e "profundamente atrelados a processos históricos" que tanto professores quanto alunos compartilham. Não há construção de conhecimento onde se nega a possibilidade de confrontação direta e resultante desestabilização dos saberes já trazidos de fora para dentro da sala de aula - incluídos aí, obviamente, os preconceitos e os estereótipos.

Em termos da relação específica entre língua de si e língua do outro, uma tal desestabilização pode se dar quando o contato com a língua do outro revela as diferenças dentro da própria língua, e não quando se procura "absorver" a língua 
do outro como entidade (radicalmente) alheia. Skliar, ao comentar a experiência de Jacotot, nos lembra:

Foi a língua do outro que fez o entendimento nascer, respirar, sobreviver, se aventurar na experiência intelectual. Não foi o milagre da língua francesa, mas a intensa diferença na própria língua que fez com que os alunos conseguissem por em funcionamento aquilo de tudo está em tudo [...] [Tratava-se de] pensar a outra língua para pensar a diferença, para ter uma experiência da diferença, para ser diferentes. (SKLIAR, 2003, p. 237-8)

O que acreditamos representar um paradoxo mais profundo, a partir da breve análise dos seis trechos acima, é o fato de justamente as recomendações aí contidas, quando confrontadas, concorrerem para um silenciamento de conflitos que afetam a própria constituição das subjetividades de professores e alunos (CORACINI, 1999; BRAGA, 2014; KUMARAVADIVELU, 2012). O fato de figurarem no livro didático sujeitos das mais diversas identidades sociais, seja como personagens ou como temas representados, refletindo assim uma visão multicultural e inclusiva da sociedade, não necessariamente contribui para um questionamento do fato de determinados grupos serem repetidamente excluídos, sub-representados ou discriminados, na sociedade $e$ nos livros didáticos.

A mera inclusão por meio da visibilidade, da mesma forma que a mera exclusão por critérios a priori (lembremos ainda a "ameaça propagandística" da marca de refrigerante), pode contribuir para um processo de naturalização da multiplicidade, concebida no material didático como abarcando homogeneidades harmônicas que se fortalecem enquanto homogeneidades enquanto se lhes extrai qualquer elemento conflituoso - o que, em certos casos, poderia constituir um autêntico "choque" de representação para sujeitos (alunos e professores) que convivem com quadros bem menos felizes e mais problemáticos em suas realidades extra-sala de aula. Insistir no politicamente correto sem problematizá-lo contribuiria, em última instância, para formar cidadãos reprodutores de uma lógica social que silencia conflitos e visa ao consenso (TODD, 2009) mais do que propriamente busca enfrentá-los em sua dimensão inconciliável.

Se estamos corretos nessa análise, teríamos diante de nós um livro que pouco favorece o confronto questionador dos saberes, tendendo a ser rapidamente absorvido pela lógica rotineira da didática dos conteúdos. Tal livro pode até se prestar, como qualquer outro livro no sentido da pedagogia de Jacotot (um Telêmaco, um texto religioso, uma carta), a ensinar alguém a ler em uma língua estrangeira, mas dificilmente escapará da lógica da explicação enquanto dele se fizer um uso meramente instrumental, ritualístico - estando estruturado lição a lição, atividade a atividade, com seus gabaritos e instruções/sugestões ao professor. Ainda que se 
proponha a tratar da língua como espaço de construção de conhecimento, algo mais que um instrumento de expressão e comunicação, o livro dificilmente o fará se os "riscos" de uma relação conflituosa entre saberes forem, desde sua concepção, estrategicamente contornados.

\section{APRENDER A JOGAR JOGANDO}

Neste ponto, a discussão nos traz de volta para o princípio da igualdade das inteligências. Vejamos: "Em que lição paramos? Em que série vocês aprenderam a dizer as horas? a fazer um pedido numa lanchonete? a usar o simple past? Isso se chama present perfect, mas vocês só irão aprender esse tempo verbal no ano que vem. Tais e tais unidades do livro serão cobradas na prova". Enunciados dessa natureza habitam o cotidiano mais familiar de uma sala de aula no ensino básico e remetem a justamente este papel do livro didático: o de garantir que haverá sempre uma desigualdade de inteligências e que o aluno não somente precisará dele e do professor para seguir aprendendo, como também, no caso de efetivamente aprender, estará sempre em uma etapa inferior rumo ao aprendizado global - aprendizado que, no caso da língua estrangeira, implica supostamente que se comprovem o domínio, a fluência e a proficiência. Haverá sempre níveis mais altos de complexidade do inesgotável saber que as disciplinas encerram e prometem. Opera-se com a perspectiva de um permanente adiamento: "quando você se formar, você poderá ser igual a mim, poderá ensinar o que eu ensino". A igualdade, desta forma, é algo que está sempre por vir, tornando-se uma conquista infinitamente adiável.

Cabe assinalar que, ao longo da história da educação, a identidade do professor como a figura que detém e transmite o conhecimento, aquele que ilumina e guia os caminhos da aprendizagem, sofreu modificações cada vez mais condizentes, em princípio, com um horizonte prospectivo da igualdade: podemos ser todos iguais uma vez dotados de uma inteligência racional, voltada ao desenvolvimento pleno das capacidades inerentes e essenciais à condição humana as quais nos permitem fazer, aprender e conhecer as coisas do mundo. Assim, do Mestre intelectual generalista, conhecedor da cultura e dos valores universalmente reconhecidos como promotores desse pleno desenvolvimento, passamos pela figura do professor especialista em sua disciplina, capaz de garantir a aprendizagem por didática e metodologia apropriadas (incluindo aí, obviamente, o uso de recursos materiais como o livro didático). Daí, a chegarmos mais recentemente a configurações identitárias afinadas com o discurso da educação como gestão: as do facilitador, instrutor, professor-tutor, monitor, ou 
mesmo motivador. Estas podem ser consideradas variantes de uma subjetivação relacional, movida pela colaboração e pelo compartilhamento e co-construção do conhecimento, sem necessariamente chamar para si a responsabilidade por um "produto final" homogêneo e mensurável do processo de ensino-aprendizagem. Entretanto, como não nos deixa esquecer Rancière, permanece insistente ao longo desse lento processo de modificações (e co-existências) o mesmo pressuposto de desigualdade das inteligências, a qual deverá ser "corrigida" por meio de uma maior aproximação entre saberes e sabedores visando à construção de uma condição de igualdade enquanto auto-realização: destino final e justificativa da própria existência humana. Do ponto de vista de uma pedagogia conduzida por mestres ignorantes, trata-se certamente de um impasse.

No percurso argumentativo que vimos traçando até aqui, uma possível saída para tal impasse reside, acreditamos, no modo como se começa a falar: do modo como se propõe a ensinar, e ensinar com um só livro distribuído para todas as inteligências. "Tudo depende se o falar e o agir de alguém partem do pressuposto da igualdade e são dirigidos a sua verificação, ou se partem do pressuposto da desigualdade" (BINGHAM; BIESTA, 2010, p. 149). Tratar-se-ia de garantir, desde o início, que os sujeitos envolvidos tragam, de fato, "seus começos" e possam agir sobre eles e os "começos dos outros".

No que concerne especificamente às aulas de língua inglesa no ensino básico, verifica-se sem muito esforço que os alunos trazem para a sala de aula um conhecimento tácito construído a partir de suas vivências. Por exemplo, é muito provável que eles estejam envolvidos em práticas de letramento digital que mobilizem, direta ou indiretamente, o uso da língua estrangeira. No entanto, o que se observa é que esses saberes tendem a ser pouco mobilizados, ou simplesmente desconsiderados, em nome de uma estrutura curricular que privilegia um sequenciamento previsível e descontextualizado da aprendizagem, pautandose basicamente por funções comunicativas ou tópicos gramaticais. Acreditamos que esse circuito segue sendo difícil de quebrar, ainda que se adotem os livros aprovados no PNLD, e que continue havendo resistência a mudanças nas práticas efetivamente realizadas no cotidiano escolar.

$\mathrm{Na}$ busca de uma base segura para conduzir a rotina de sala de aula, muitas vezes onerada pelo grande número de horas trabalhadas e de alunos em sala de aula, opta-se pela uniformidade, padronização e previsibilidade das atividades, condições que o livro didático, por mais "aberto" que possa ser, também permite fomentar. Assim, do ponto de vista dos autores de livro didático, não haveria como intervir nessa lógica a não ser por meio de uma proposta verdadeiramente autônoma 
de estruturar os conteúdos (MAGNO E SILVA, 2009; KUMARAVADIVELU, 2006/2009).

Seria preciso que os autores de livro didático estivessem atentos a alguns princípios norteadores que podem, em certa medida, se alinhar aos critérios circunstanciados dos editais para elaboração, mas também os podem ultrapassar. Dentre esses princípios estariam, como sugere Littlejohn (2012, p. 295): a nãocumplicidade com a "roteirização" (scripting) dos acontecimentos em sala de aula, aí incluídas as interações aluno-professor e aluno-aluno; a elaboração de atividades abertas e que tenham o potencial de produzir resultados únicos cada vez que são propostas; a inclusão de notas ao professor que encorajem e apoiem a experimentação; e, sobretudo, conteúdos que reflitam uma concepção de ensinoaprendizagem de língua estrangeira como algo não restrito a programas nivelados ou sequências bem organizadas e prescritivas de atividades visando à aquisição de habilidades e competências.

Em uma dimensão mais ampla, haver-se-ia de levar em conta o modo particular com que se constroem e se interrelacionam os saberes em grande parte das práticas sociais em que nos vemos inseridos na contemporaneidade. Pensamos aqui, especificamente, no que Lankshear e Knobel (2011) chamam de epistemologia da performance. Inspirados no conceito wittgensteiniano de saber como resultado de se "jogar um jogo" e se descobrirem as "regras" desse jogo conforme se joga, os autores argumentam que cada vez mais os indivíduos têm contado com práticas auxiliadas pelas novas tecnologias para realizar tarefas para as quais não há padrões claros (ou pelo menos não ensináveis de forma tradicional) de proceder ${ }^{6}$. Dentre essas práticas, estariam a bricolagem, a colagem e a montagem, operações por meio das quais conhecimentos são produzidos em plena interação entre os elementos envolvidos - quer com os indivíduos lidando diretamente com a tecnologia, quer com eles interagindo entre si por meio da tecnologia. São operações que, em princípio, podem funcionar como facilitadoras do tipo de presença (coming into presence) que, conforme vimos, Biesta advoga para uma prática pedagógica verdadeiramente emancipadora.

É certo que os materiais disponíveis no mercado têm incorporado, cada vez mais, componentes digitais e/ou multimídia como parte de seus pacotes. Além disso, há um número significativo de fontes gratuitas de material didático

6 Tais conexões nos levam a uma irresistível analogia entre o aluno holandês de Jacotot tentando ler uma aventura épica em uma língua que desconhece (o francês) no século XIX e um aluno brasileiro, no século XXI, tentando (e efetivamente se saindo muito bem em) jogar um videogame cujas regras, comandos e ações se dão exclusivamente em inglês - ainda que o conhecimento dessa língua por parte do jogador seja mínimo. 
online. Não surpreende, portanto, que os editais de elaboração de livros didáticos já contemplem o componente digital, sendo ele uma das peças das coleções que podem ser submetidas à análise. Tal fato nos permite supor que já há um amplo reconhecimento da dimensão digital como parte integrante dos materiais didáticos adotados nas diversas disciplinas do ensino básico. O que ocorre, no entanto, é que os materiais ainda tendem a replicar - ou meramente "repaginar" - boa parte da lógica do impresso em uma interface digital que funciona apenas a meio caminho. Nesse sentido, o exercício de uma epistemologia da performance a serviço da aprendizagem autônoma continua a ser algo tangencial, uma prática contingente que pode até vir a acontecer quando se trata de transpor para um novo suporte os mesmos tipos de atividades que compõem tradicionalmente os materiais impressos.

Ainda que o sentido propriamente exploratório do saber - professor e alunos trabalhando juntos para descobrir, aprender e ensinar coisas que não sabiam antes de adentrar a prática - se potencialize com o uso dos componentes digitais propostos como material didático, é grande a chance de que a lógica da explicação venha a se sobrepor quando alunos (e, especialmente, o professor) se encontrarem em situação vulnerável diante de saberes que começam a tomar rumos inesperados, traçados ao longo de uma rota sem começo, meio e fim pré-determinados. Em última análise, com toda a inovação tecnológica, o foco do ensino de línguas estrangeiras no ensino básico corre o risco de seguir focando mais na leitura de códigos - por mais que as estratégias de ensino-aprendizagem se apresentem como facilitadoras da autonomia - do que na construção de significados que possam, eventualmente, se contrapor a uma lógica racionalizante e previsível de aquisição de competências e habilidades.

\section{CONCLUINDO: POR UMA LÓGICA DA REAPROPRIAÇÃO}

Se o livro didático é, e provavelmente continuará sendo, em coleções, formatos digitais ou formas alternativas de cadernos e apostilas, o instrumento mais utilizado para o ensino de uma língua estrangeira na escola, seria desejável que ele, afinal de contas, se prestasse a função semelhante à do livro de Rancière sobre a história de Jacotot. Este conta uma narrativa que não deve ser tomada como exemplar, tampouco como uma metodologia generalizável. O método universal de Jacotot não é propriamente um método, um conjunto de receitas a serem seguidas e replicadas escolas afora: não o era há duzentos anos e nem o seria hoje, o que, de resto, ambos Jacotot e Rancière insistiram em sublinhar. Ele é, antes, uma narrativa - uma história sobre ensinar e aprender que nos convoca a traduzir, ou reapropriar, 
uma história a partir da qual outras poderão ser contadas. Nos dizeres de Bingham e Biesta,

[O Mestre Ignorante] é educativo precisamente no sentido de que obriga o leitor a traduzir o seu conteúdo para a sua experiência, sem qualquer certeza de como esse conteúdo deve ser traduzido. Equivale a dizer, o livro é para ser lido sem um ensinamento. [...] Aprende-se, mas somente na [pela] história. (BINGHAM; BIESTA, 2010, p. 151-2)

A sugestão, obviamente, funciona aqui como uma centelha para quem irá trabalhar o livro didático de modo mais verdadeiramente emancipador. O professor de língua estrangeira ou de outras disciplinas por certo continuará se valendo dele se não, de outros materiais de apoio - para ensinar. E continuará fazendo com que os alunos o leiam como estando a serviço de um grande ensinamento, um legado de saberes nunca plenamente alcançáveis em sua totalidade: afinal, haverá sempre uma habilidade adicional a se aprender e uma posição hierarquicamente superior de saber-poder a se almejar.

O questionamento que se coloca a partir daí, e com o qual encerramos este trabalho, é: até que ponto, ou exatamente em quais pontos, em um determinado contexto de ensino-aprendizagem como o do ensino básico brasileiro, a engrenagem pedagógica que parte dos parâmetros e diretrizes curriculares, passando pela elaboração do material propriamente, sua avaliação e efetiva adoção, é capaz de interromper a lógica de explicação e deixar intervir, autonomamente, as vozes de quem aprende, as vozes de quem ensina, as vozes de quem aprende, ensina e aprende novamente, "ignorantemente", com ou sem o intermédio de um livro? Em que medida, ou até que ponto, a reapropriação de saberes pode tomar a frente da explicação - na sala de aula $e$ na sociedade - apontando para caminhos novos, imprevisíveis?

\section{REFERÊNCIAS BIBLIOGRÁFICAS}

BIESTA, G. (2006). Beyond Learning: Democratic Education for a Human Future. Boulder: Paradigm. BINGHAM, C.; BIESTA, G. (2010). Rancière: Education, Truth, Emancipation. London and New York: Continuum.

BRAGA, M. D. W. (2014). O discurso sobre o livro didático de inglês: a construção de verdade na sociedade de controle. São Paulo. 246p. Tese de Doutorado - Faculdade de Filosofia, Letras e Ciências Humanas, Universidade de São Paulo. 
BRASIL. (2009). Edital de convocação para o processo de inscrição e avaliação de coleções didáticas para o Programa Nacional do Livro Didático 2011. Brasília: Ministério da Educação, Secretaria de Educação Básica. Disponível em < ftp://ftp.fnde.gov.br/web/livro didatico/edital pnld_2011.pdf $>$. Acesso em: 22 jan. 2015.

BRASIL. (2012). Edital de convocação para o processo de inscrição e avaliação de coleções didáticas para o Programa Nacional do Livro Didático 2014. Brasília: Ministério da Educação, Secretaria de Educação Básica. Disponível em < http://www.fnde.gov.br/arquivos/category/165editais?...pnld-2014-edital...3 > . Acesso em: 22 jan. 2015.

CORACINI, M. J. (org.). (1999). Interpretação, autoria e legitimação do livro didático. Campinas: Pontes.

CORACINI, M. J. (2014). Entre a modernidade e a pós-modernidade: discurso e ensino. In: Educação, vol. 37 (3), p. 400-411.

DIAS, R.; CRISTÓVÃO, V. L. L. (orgs.) (2009). O livro didático de língua estrangeira: múltiplas perspectivas. Campinas: Mercado de Letras.

FERREIRA, A. J. (org.). (2014). As políticas do livro didático e identidades sociais de raça, gênero, sexualidade e classe em livros didáticos. Campinas: Pontes.

GALLOWAY, S. (2012). Reconsidering Emancipatory Education: Staging a Conversation Between Paulo Freire and Jacques Rancière. In: Educational Theory, vol. 62 (2), p. $163-$ 184.

JORDÃO, C. M. (2014). Aprendendo língua estrangeira com o professor Jacotot: criticidade na pedagogia crítica e no letramento crítico. In: MATEUS, E.; OLIVEIRA, N. Estudos críticos da linguagem e formação de professores de línguas: contribuições teórico-metodológicas. Campinas: Pontes.

KUMARAVADIVELU, B. (2006/2009). Understanding Language Teaching: From Method to Postmethod. Mahwah: Lawrence Erlbaum.

KUMARAVADIVELU, B. (2012). Individual Identity, Cultural Globalization and Teaching English as an International Language: The Case for an Epistemic Break. In: ALSAGOFF, L. et al. (orgs.). Teaching English as an International Language: Principles and Practices. New York: Routledge, p. 9-27. 
LANKSHEAR, C.; KNOBEL, M. (2011). New Literacies: Everyday Practices and Social Learning, $3^{\mathrm{a}}$ ed. New York: McGraw Hill/Open University Press.

LITTLEJOHN, A. (2012). Language Teaching Materials and the (Very) Big Picture. In: Electronic Journal of Foreign Language Teaching, vol. 9 (1), p. 283-297.

MAGNO E SILVA, W. (2009). Livros didáticos: fomentadores ou inibidores da autonomização? In: DIAS, R.; CRISTÓVÃO, V. L. L. (orgs.). O livro didático de língua estrangeira: múltiplas perspectivas. Campinas: Mercado de Letras, p. 57-78.

PELLETIER, C. (2012). No Time or Place for Universal Teaching: The Ignorant Schoolmaster and Contemporary Work on Pedagogy. In: DERANTY, J.-P.; ROSS, A. (orgs.) Jacques Rancière and the Contemporary Scene. London and New York: Bloomsbury, p. 99115.

RAMOS, R. (2009). O livro didático de língua inglesa para o ensino fundamental e médio: papéis, avaliação e potencialidades. In: DIAS, R.; CRISTÓVÃO, V. L. L. (orgs.). O livro didático de língua estrangeira: múltiplas perspectivas. Campinas: Mercado de Letras, p. $173-198$.

RANCIÈRE, J. (1987/2002). O mestre ignorante - cinco lições sobre emancipação intelectual. Trad. Lílian do Valle. Belo Horizonte: Autêntica.

RANCIÈRE, J. (2000/2009) A partilha do sensivel: estética e política. Trad. Mônica Costa Netto. São Paulo: Editora 34.

RANCIÈRE, J. (2010). On Ignorant Schoolmasters. In: BINGHAM, C.; BIESTA, G. Rancière: Education, Truth, Emancipation. London and New York: Continuum, p. 1-24.

ROJO, R.; BATISTA, A. A. G. (orgs.). (2003). Livro didático de lingua portuguesa, letramento e cultura da escrita. Campinas: Mercado de Letras.

RUITENBERG, C. (2008). What If Democracy Really Matters? In: Journal of Educational Controversy, vol. $3(1), \mathrm{s} / \mathrm{p}$.

SKLIAR, C. (2003). Jacotot-Rancière ou a dissonância inaudita de uma pedagogia (felizmente) pessimista. In: Educação e Sociedade, vol. 24 (82), p. 229-240.

TILIO, R. C. (2006). O livro didático de inglês em uma abordagem sócio-discursiva: culturas, identidades e pós-modernidade. Rio de Janeiro. 258p. Tese de Doutorado - Departamento de Letras, Pontifícia Universidade Católica do Rio de Janeiro. 
TODD, S. (2009). Toward an Imperfect Education: Facing Humanity, Retbinking Cosmopolitanism. Boulder, London: Paradigm Publishers.

TREVISAN, A. L. (2010) A pragmática do professor e a experiência de liberdade educativa. In: PAGNI, P. A.; GELAMO, R. P. (orgs.). Experiência, educação e contemporaneidade. Marília: Poiseis, p. 213-228.

VALLE, L. (2003). Pedra de tropeço: a igualdade como ponto de partida. In: Educação e Sociedade, vol. 82 (24), p. 259-266.

VERMEREN, P.; CORNU, L.; BENVENUTO, A. (2003). Atualidade de O Mestre Ignorante [Entrevista com Jacques Rancière]. In: Educação e Sociedade, vol. 24 (82), p. 185-202.

Recebido: 09/02/2015

Aceito: 17/06/2015 